Dieses Dokument ist eine Zweitveröffentlichung (Postprint) /

This is a self-archiving document (accepted version):

Thomas Linde, Karsten Backhaus, Jürgen Stahl, Theo Kaffenberger

Comparison of the Dissipation Factor of Insulating Resins With and Without Anhydride Curing Agents

Erstveröffentlichung in / First published in:

IEEE 3rd International Conference on Dielectrics (ICD). Valencia, 2020. IEEE. ISBN 978-17281-8983-3

DOI: https://doi.org/10.1109/ICD46958.2020.9341819

Diese Version ist verfügbar / This version is available on:

https://nbn-resolving.org/urn:nbn:de:bsz:14-qucosa2-764050 


\section{Comparison of the Dissipation Factor of Insulating Resins With and Without Anhydride Curing Agents}

\author{
Thomas Linde, Karsten Backhaus \\ Institute of Electrical Power Systems \\ and High Voltage Engineering \\ Technische Universität Dresden \\ Dresden, Germany \\ jan_thomas.linde@tu-dresden.de
}

\author{
Jürgen Stahl \\ VEM Sachsenwerk GmbH \\ Dresden, Germany
}

\author{
Theo Kaffenberger \\ Von Roll Schweiz AG \\ Breitenbach, Switzerland
}

\begin{abstract}
The most main wall insulations of rotating electrical high voltage machines consists of several layers of wound mica tape impregnated with epoxy resins. Methylhexahydrophthalic anhydride and Hexahydrophthalic anhydride are the state-of-theart curing agents in epoxy insulations and are therefore essential components of the insulation system. Both anhydrides were proposed to the candidate list of Substances of Very High Concern and are therefore part of the European REACH authorization process. The prohibition or restricted use of both anhydrides in Europe in the future is possible and puts high pressure on the European manufacturers of electrical devices. Possible substitutes are available, but have to be qualified e.g. with respect to their dielectric properties. Hence, this paper compares several insulating resin systems with and without anhydride curing agents regarding their dielectric loss behavior. The results reveal that the curing agent has a measurable effect on the dielectric losses. Furthermore, the investigated anhydride-free insulation systems are a viable substitute at least with regard to their dielectric losses.
\end{abstract}

\section{INTRODUCTION}

The main wall insulation of rotating electrical high voltage machines is exposed to significant thermal, electrical, ambient (e.g. moisture) and mechanical stress. Commonly, a combination of mica tapes and epoxy resin is utilized as an insulation system [1]. The majority of modern epoxy-mica insulations are fabricated in a vacuum pressure impregnation (VPI) process plus the subsequent curing [1]. The epoxy resin can consist of several parts: the epoxy resin Diglycidylether of Bisphenol A (DGEBA) itself, the curing agent and, possibly, an accelerator. The different combinations of epoxy, accelerator, curing agents and curing processes lead to a number of combinations of epoxy types that are presented in chapter II. Two of the most common curing agents are Hexahydromethylphthalic Anhydride (MHHPA) and Hexahydrophthalic Anhydride (HHPA) [2]. Both of them are listed as candidates for Substances of Very High Concern (SVHC) due to their possible negative effects on the human respiratory system during the curing process [3]. (M)HHPA is therefore part of the REACH regulation process which will lead to a restricted use or a prohibition in the future. As of 2019, an estimated date for the restricted use of (M)HHPA could be 2023 [4]. Manufacturers of high voltage rotating machines and their suppliers argue against the priorization in the $\mathrm{REACH}$ process with high socio-economic consequences and the very low numbers of accidents when handling epoxies and anhydrides [5]. Another argument is the lack of already qualified suitable alternatives to both substances [2]. In the meantime, chemical suppliers offer epoxy systems without (M)HHPA [2], [6]. Within the highly stressed insulation, one important aspect are the dielectric losses of the insulation materials. The measurement of the dielectric loss factor $\tan \delta$ is specified in DIN EN 60034-27-3 [7]. Besides the intrinsic properties of the insulation materials, moisture and faults like delamination can be detected by measuring $\tan \delta$ [8]

\section{INSULATION OF STATOR WINDING INSULATION}

During the manufacturing process, the metallic stator bars of rotating electrical machines are wound with mica tape. The mica tape may contain an accelerator. After wrapping and evacuating, the impregnation system is introduced and pressurized to fill out the remaining space within and around the tapes. The impregnation system is usually made of epoxy and a curing agent. In electrical devices, anhydride curing agents are widespread due to the good electrical properties of the resultant resin. Finally, the curing of the impregnated system can be performed at room or elevated temperature [9]. The accelerator supports the polyaddition during the curing process. The multitude of different available materials leads to a variety of combinations that can be used and qualified for the manufacturing process of electrical machines. Besides the electrical properties of the cured insulation, several factors play a role when deciding on a epoxy-curing agent combination e.g. emission of environmentally unfriendly volatile organic compounds (VOC) and difficulty of material handling during manufacturing. Many impregnation systems base on DGEBA and the curing agent (M)HHPA. Alternatives to the (M)HHPA as a curing agent are presented in the following.

\section{A. Insulation Systems without MHHPA or HHPA}

A possible substitute to (M)HHPA is Methyltetrahydrophthalic Anhydride (MTHPA). MTHPA is also an anhydride curing agent but not listed as SVHC, therefore MTHPA could be seen as an (at least mid-term) replacement for the (M)HHPA curing agents. Alternatively, insulation systems without anhydride curing agents are available e.g. some catalyzed epoxy resins without VOC. Finally, resins based on un- 
saturated polyesterimide (UPI) are available. The (M)HHPAfree epoxies should have comparable or better characteristics as the (M)HHPA-containing systems.

\section{B. Variation of the Tape Carrier}

The muscovite of the mica tape can be either applied on a glass fabric or a polyester carrier. The carrier material and the existence and type of accelerator influences the dielectric properties of the entire system [10] so that both available options are included in this investigation.

\section{DielECTRIC DisSiPATION FACTOR}

The terms loss tangent $\tan \delta$ and dielectric loss factor are used synonymously to dielectric dissipation factor (DDF). The DDF of electrical machine insulation is measured in order to safeguard constant manufacturing quality of the insulation materials and the insulation system. The aging condition of insulation can be monitored and evaluated by measuring the DDF [7]. Although partial discharges (PD) in the insulation cause losses, the DDF is not suitable for reliable detection and localization of PD.

One major influence factor on the DDF is the temperature. Polarization and conduction in the solid insulation material change significantly with increasing temperature. For example, [11] finds that the insulation resistance of epoxy-mica insulation decreases by approximately two decades in the range from $20^{\circ} \mathrm{C}$ to $100^{\circ} \mathrm{C}$, leading to significantly larger conduction losses in the epoxy. Additionally, the polarization mechanisms are temperature-sensitive, which influences the dielectric loss due to electrical relaxation in the material. Modern main wall insulation systems are usually made for temperature class $\mathrm{F}$ or higher, corresponding to at least $155^{\circ} \mathrm{C}$ of allowed permanent temperature [12]. In operational use, electrical machines are exposed to significant thermal stress. Hence, in this investigation, the DDF measurements are carried out for $23^{\circ} \mathrm{C}, 80^{\circ} \mathrm{C}$ and $155^{\circ} \mathrm{C}$. The researchers in [2] state that a DDF of $100 \cdot 10^{-3}$ is desirable for the main wall insulations systems at a temperature of $155^{\circ} \mathrm{C}$.

\section{TEST SETUP}

A digital measurement system with a specified resolution of $\tan \delta<1 \cdot 10^{-6}$ measures the DDF. A gas standard capacitor with $\tan \delta<1 \cdot 10^{-5}$ is used as reference. The high voltage (HV) transformer is fed by an high accuracy amplifier, ensuring very low harmonic distortion THD $<0.01 \%$ (Fig. 1). The voltage is varied from $20 \%$ to $120 \%$ of the rated insulation system voltage of $V_{\mathrm{R}}=11 \mathrm{kV}$.

\section{A. Test Specimens}

The specimens were produced and delivered by the manufacturer according to their usual manufacturing instructions. For different specimens each a polyester and a glass fabric carrier mica tape was utilized. Of each combination, three samples are examined for statistical significance. Tab. I shows the different combination of available resins (DGEBA and UPI) and anhydride curing agents (MHHPA, MTHPA, none).

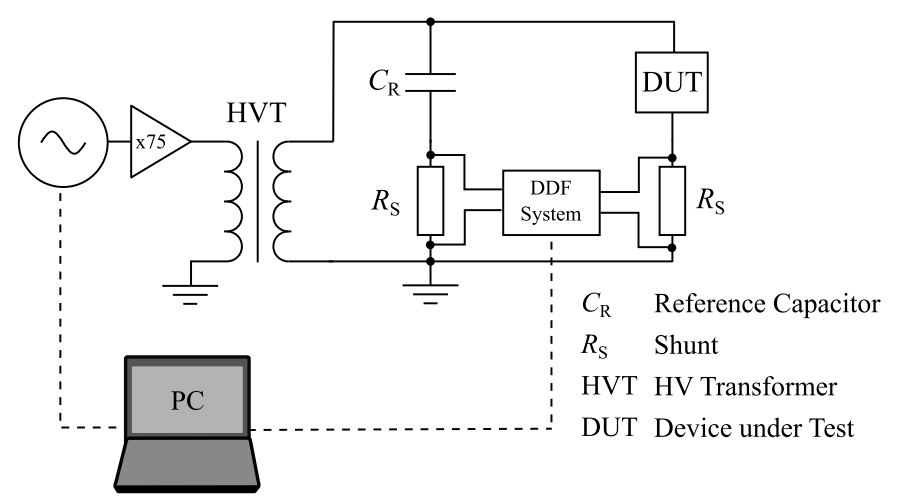

Fig. 1. Test setup with a digital DDF measuring system

TABLE I

OVERVIEW OF INVESTIGATED SPECIMENS

\begin{tabular}{l|l|l|l|l}
\hline Code & Resin & $\begin{array}{l}\text { Anhydride } \\
\text { Curing Agent }\end{array}$ & $\begin{array}{l}\text { Additional } \\
\text { Info }\end{array}$ & $\begin{array}{l}\text { REACH } \\
\text { Candidate }\end{array}$ \\
\hline A & DGEBA & MHHPA & & yes \\
B & DGEBA & MTHPA & & no \\
C & DGEBA & MTHPA & catalyzed & no \\
D & DGEBA & none & catalyzed & no \\
E & UPI & none & no VOC & no \\
F & UPI & none & & no \\
\hline
\end{tabular}

Some of the epoxy systems contain a catalyst influencing the curing process. One of the two available UPI resins has no diluents leading to no emission of VOC.

\section{B. Sample Preparation}

The samples were prepared according to [7]. The standard requires a guard ring arrangement that is applied on the outer layer of the insulation. Conductive paint was used for the electrode and guard ring. The insulating gap is $1 \mathrm{~mm}$ wide and additionally insulated by applied insulating temperaturestable silicone to avoid surface discharges within the gap. The outer electrodes are contacted by a copper band to the measuring impedance or to ground potential respectively. The samples were stored under indoor conditions: $(23 \ldots 25){ }^{\circ} \mathrm{C}$ and (40...60) \% relative humidity.

\section{Measurement Procedure}

The voltage is increased stepwise from $0.2 V_{\mathrm{R}}$ to $1.2 V_{\mathrm{R}}$ as specified in [7]. The average $\tan \delta$ is recorded for $20 \mathrm{~s}$ at each voltage step. The values of interest are listed in Tab. II.

At higher voltages $(1.0 \ldots 1.2) V_{\mathrm{R}}$ and temperatures $(80 \ldots 155)^{\circ} \mathrm{C}$, some test specimens show strong surface discharges in the vicinity of the guard ring. Despite being additionally insulated with silicone in the gap between measurement electrode and guard ring, the results could not be measured with adequate accuracy and are therefore not presented in order to rule out any influence on the results. 


\section{RESUlts}

\section{A. IEC-compliant Measurements at Room Temperature}

The values of all three measured samples of each specimen at $23{ }^{\circ} \mathrm{C}$ type are in good agreement. A constant DDF across for voltages up to $1.2 V_{R}$ is desirable. The anhydride-based resin systems show low and constant DDF values below $7 \cdot 10^{-3}$ across the entire voltage range. The measured DDF of the anhydride-free resin increases with increasing voltage. This behavior is especially pronounced for the UPI resins (E, F) as can be seen in Fig. 2.

A comparison to the characteristic IEC values [7] shows that all measured values except for the UPI resin (F) are within the limits at room temperature (Tab. III).

Generally, the measured DDF values are slightly lower with the polyester tape specimens compared to glass fabric specimens (Fig. 3). The catalyzed epoxy resin without anhydrid curing agent (D) even shows significantly lower losses in comparison to measurements with glass fabric.

TABLE II

Characteristic Values at RoOM Temperature aCCORding to [7]

\begin{tabular}{l|l|l|l}
\hline & Characteristic Value & Target Value \\
\hline I & $\begin{array}{l}\text { initial DDF at } 0.2 V_{\mathrm{R}} \\
\text { II }\end{array}$ & $\begin{array}{l}\text { largest DDF change between two } \\
\text { voltage steps }\end{array}$ & $\Delta \tan \delta_{0.2}$ \\
III & $\begin{array}{l}\text { DDF change between } 0.2 V_{\mathrm{R}} \text { and } \\
0.6 V_{\mathrm{R}}\end{array}$ & $\Delta \tan \delta_{0.6-0.2}$ & $<5 \cdot 10^{-3}$ \\
\hline
\end{tabular}

TABLE III

COMPARISON OF THE MEASUREMENT TO IEC VALUES [7]

\begin{tabular}{l|r|r|r}
\hline & $\begin{array}{r}\tan \delta_{0.2} \\
\text { in } 10^{-3}\end{array}$ & $\begin{array}{r}\Delta \tan \delta_{0.2} \\
\text { in } 10^{-3}\end{array}$ & $\begin{array}{r}\Delta \tan \delta_{0.6-0.2} \\
\text { in } 10^{-3}\end{array}$ \\
\hline IEC Limit & 20 & 5 & 5 \\
\hline A & 4.5 & 0.1 & 0.1 \\
B & 4.7 & 0.1 & 0.1 \\
C & 6.7 & 0.2 & 0.1 \\
D & 7.0 & 1.2 & 1 \\
E & 8.1 & 2.8 & 0.6 \\
F & 10.1 & 2.9 & $\mathbf{5 . 4}$ \\
\hline
\end{tabular}

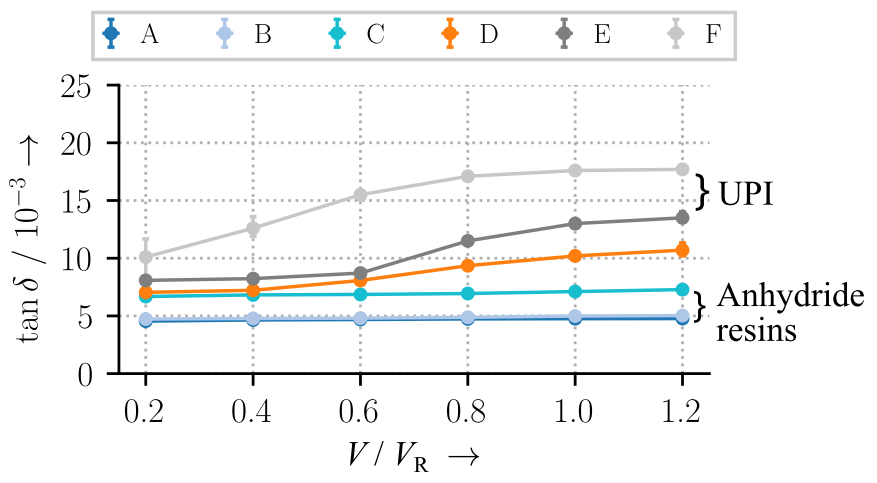

Fig. 2. DDF of glass fabric specimens at $23^{\circ} \mathrm{C}$

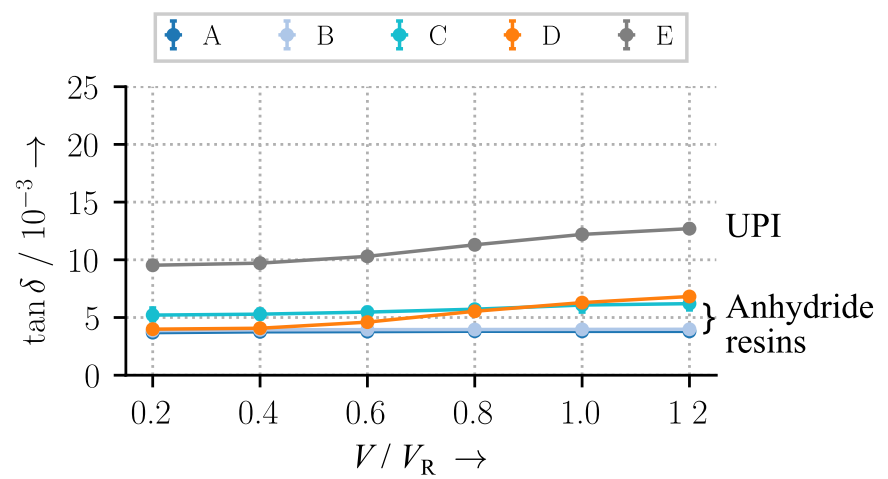

Fig. 3. DDF of polyester carrier specimens at $23^{\circ} \mathrm{C}$

\section{B. Measurements at Elevated Temperature}

In this section, only measurements with glass fibre carrier at $80^{\circ} \mathrm{C}$ are presented (Fig. 4). While the DDF of the anhydridebased resins (A-C) increases between $44 \%$ and $57 \%$ on average, the DDF of the catalyzed anhydride-free resin (D) increases by $70 \%$ and even by $94 \%$ for the UPI (E, F) compared to the $23^{\circ} \mathrm{C}$ measurement. The reason for the missing data points at higher voltages is given in section IV-C.

The measurement results in Fig. 5 shows that the DDF is increased significantly for all specimens when heated up to $155^{\circ} \mathrm{C}$. The spread of the measured DDF has increased especially for the UPI (E) and anhydride-free resin (D). The anhydride-based resins A, B, and C have comparably low and nearly constant DDF values below $50 \cdot 10^{-3}$. The diluent-free UPI (E) has the highest DDF values, but still below $100 \cdot 10^{-3}$. The uncatalyzed MTHPA resin (B) has the lowest DDF values of under $20 \cdot 10^{-3}$. All of the three measured specimens of the UPI system (F) have similar and low DDF values compared to the other UPI system.

\section{DISCUSSION}

None of the systems exceed the values set by the IEC standard [7] at room temperature significantly. Still, it is remarkable that the anhydride-free systems show a higher DDF with increasing voltage. The increase is even higher for UPI

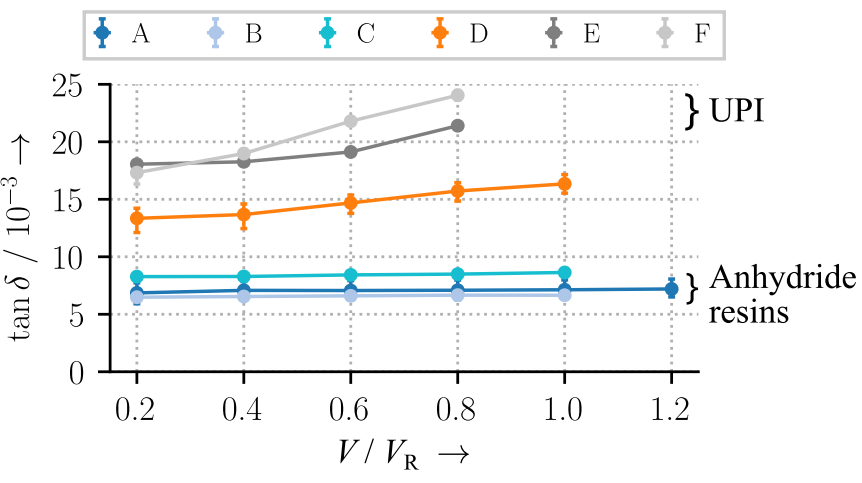

Fig. 4. DDF of glass fabric specimens at $80^{\circ} \mathrm{C}$ 


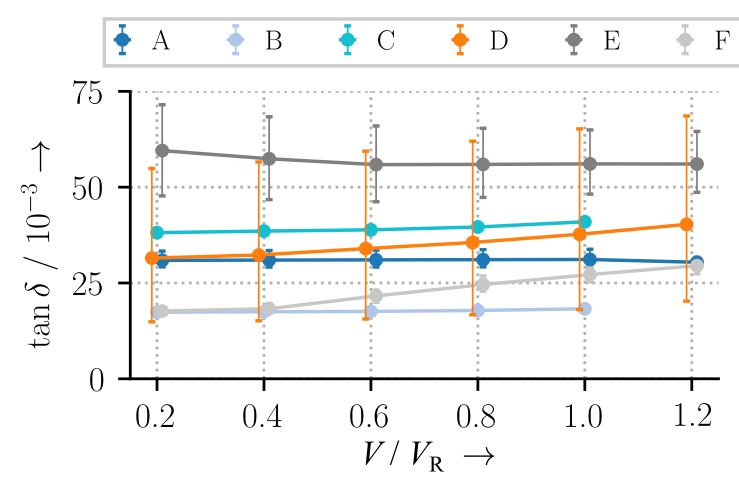

Fig. 5. DDF of glass fabric specimens at $155^{\circ} \mathrm{C}$

resins compared to anhydride-free epoxy resins. The high reproducibility of the measurements for room temperature is evidence of a high impregnation quality of the sample bars. It can be assumed that the increasing DDF has material-specific reasons e.g. an electric field strength dependent conductivity as mentioned in [11]. Measurements with a polyester tape carrier instead of a glass fabric revealed lower DDF results.

Generally, the DDF increase from $23^{\circ} \mathrm{C}$ to $80^{\circ} \mathrm{C}$ to $155^{\circ} \mathrm{C}$ can be attributed to the increase in conductivity as [11] showed and to the shift of polarization mechanisms with the temperature. Furthermore, the glass transition temperature is usually within this temperature range. The glass transition is the shift of the resin from a brittle to a rubbery state and is accompanied by significant changes in the electric and mechanical properties. [2] states that MTHPA-cured systems have much higher DDF values at high temperatures. The measurements presented do not agree entirely: the MTHPA-cured system have comparably low losses at $155^{\circ} \mathrm{C}$. Furthermore, the $\tan \delta$ of all three anhydride-based systems were well below reference point of $100 \cdot 10^{-3}$, the uncatalyzed MTHPA system even below the MHHPA system.

The recorded DDF values of the anhydride-free catalyzed system specimens confirm the measurements of [2] showing higher $\tan \delta$ values at $155^{\circ} \mathrm{C}$ than some of the anhydridebased epoxy resin. While both UPI resins had significantly high initial DDF values at low temperature, the increase of one UPI system (F) up to $155^{\circ} \mathrm{C}$ was particularly low. A plausible reason is a glass transition temperature above $155^{\circ} \mathrm{C}$ of the UPI resin $(\mathrm{F})$.

\section{CONCLUSIONS}

The DDF of several impregnation systems with and without anhydrides was measured on standardized specimens. The investigations showed that the curing agent has a measurable effect on the overall dielectric loss behavior of an insulation system. A number of alternative curing agents to the REACH candidates HHPA and MHHPA have been investigated and show comparable behaviour at all temperatures. However, there is a tendency for anhydride-based systems, such as REACH-compliant MTHPA-cured resins that are already available on the market, to have lower and more constant losses across the voltage spectrum reaching from $20 \%$ to $120 \%$ of the rated voltage. Measuring the dielectric loss factor is only one aspect of qualifying reliable and economical alternatives to the currently used anhydride curing agents. In the future, several other investigations such as long-term hightemperature performance, partial discharge aging, mechanical as well as procedural tests should be carried out. Due to the higher DDF values of anhydride-free impregnation systems, the limits set by IEC 60034-27-3 [7] need to be reconsidered.

\section{ACKNOWLEDGMENT}

The authors thank VEM Sachsenwerk GmbH and Von Roll Schweiz AG for providing the specimens. This research has been funded by the European Social Fund (ESF) and the Free State of Saxony.

\section{REFERENCES}

[1] Cigré WG A1.39, "Dielectric dissipation factor measurements on new stator bars and coils," Technical Brochure 769.

[2] C. Beisele, M. Brasch, and E. Kattnig, "New MHHPA-free epoxybased vacuum pressure impregnation systems and new mica-tapes for large generators and motors," in 13th International Electrical Insulation Conference (INSUCON), 2017.

[3] European Chemicals Agency (ECHA), ANNEX XV - SVHC DOSSIER MHHPA - CAS NO. 25550-51-0.

[4] E. Kattnig and C. Beisele, "New Anhydride-free Epoxy-based Vacuum Pressure Impregnation Systems and New Mica-tapes for Large Generators and Motors," CWIEME Berlin 2018.

[5] CEMEP and NEMA, "Prioritization with a Sense of Proportion: Anhydrides MHHPA and HHPA under the European REACH directive," Feb. 2016

[6] Von Roll, "REACH compliant solutions - Impregnation resins for highvoltage rotating machines."

[7] IEC 60034-27-3:2015, "Dielectric dissipation factor measurement on stator winding insulation of rotating electrical machines."

[8] Electric Machinery Committee, "IEEE Recommended Practice for Measurement of Power Factor Tip-Up of Electric Machinery Stator Coil Insulation," 2001.

[9] G. C. Stone, Electrical Insulation for Rotating Machines: Design, Evaluation, Aging, Testing, and Repair, 1st Edition. Piscataway, NJ, USA: Wiley-IEEE Press, 2004.

[10] Z. Bezděk, "Accelerators of Epoxy-Anhydride Binders for VPI Insulation System of High-Voltage Rotating Machine Windings," in Proceedings of the 21st International Symposium on High Voltage Engineering, 2019.

[11] L. Lamarre and E. David, "Temperature dependence of the resistance of modern epoxy mica insulation of HV rotating machines," IEEE Transactions on Dielectrics and Electrical Insulation, vol. 15, no. 5, Oct. 2008.

[12] IEC 60085:2007, "Electrical insulation - Thermal evaluation and designation." 